\title{
Nitroxyl radical self-assembled monolayers: Generalized lateral interactions model used with binary electrolyte mixture
}

\author{
Olivier Alévêque *, Pierre-Yves Blanchard, Eric Levillain \\ L'UNAM Université, Université d'Angers, CNRS UMR 6200, Laboratoire MOLTECH-Anjou, 2 bd Lavoisier, 49045 ANGERS cedex, France
}

\section{A R T I C L E I N F O}

Article history:

Received 29 November 2012

Received in revised form 17 December 2012

Accepted 18 December 2012

Available online 28 December 2012

Keywords:

TEMPO

Self-assembled monolayers

Cyclic voltammetry

Lateral interactions mode

\begin{abstract}
A B S T R A C T
The electrochemical behavior of redox centers on self-assembled monolayer (SAM) was interpreted through the generalized lateral interactions model when the electrolyte medium is composed of miscible solvents. Electrochemical behaviors of nitroxyl radical SAMs provide evidence of a linear dependence of interaction parameters with the ratio of the two solvents.
\end{abstract}

(c) 2013 Elsevier B.V. All rights reserved.

\section{Introduction}

Since their discovery in 1983 [1], self-assembled monolayers of alkanethiols on gold have become an ideal system for the theoretical study of interfacial phenomena [2]. Previous works [3-6] were dedicated to develop a generalization of the Laviron's interaction model in order to extend this model to random and non-random distributions of electroactive sites on surface. Here, we propose to demonstrate the validity of this model in the case of binary electrolyte mixture. This work will focus on three aspects: (1) the continuity of interaction constants, (2) the role and (3) the stability of the distributions of electroactive centers, when you have to go from one solvent to another.

\section{Experimental}

\subsection{Materials}

All electroactive self-assembled monolayers used in this study were formed from one (SAMs) or two constituents (mixed SAMs).

The electroactive one (C15T) was composed of a 2,2,6,6tetramethylpiperidine-1-oxyl (TEMPO) unit linked to a 15-carbon thio-alkyl tail. Synthesis and characterizations of C15T were described in reference 4 . We used redox-responsive TEMPO SAMs because they are known to be electroactive and stable in both aqueous and non-aqueous solvents [7-9], especially in methylene chloride $\left(\mathrm{CH}_{2} \mathrm{Cl}_{2}\right)$

\footnotetext{
* Corresponding author. Tel.: + 33 241735090; fax: + 33241735405

E-mail address: olivier.aleveque@univ-angers.fr (O. Alévêque).
}

and acetonitrile $\left(\mathrm{CH}_{3} \mathrm{CN}\right)$, and their electrochemical characteristics can be explained by the generalized lateral interaction model [5].

The second constituent was a commercial alkanethiol, 1dodecanethiol $\left(\mathrm{C}_{12} \mathrm{H}_{25} \mathrm{SH}\right.$ - abbreviated $\left.\mathrm{C} 12 \mathrm{SH}\right)$ (Sigma-Aldrich), which acts like a passive matrix to prevent reactions directly on gold substrate.

Alkyl chain lengths of the two constituents were chosen to optimize the nanoscale organization of SAMs and allow the positioning of electroactive sites (TEMPO) on the surface of the SAM $[2,10]$.

\subsection{Gold substrates elaboration}

Au substrates were prepared by deposition of ca. $5 \mathrm{~nm}$ of chromium followed by ca. $100 \mathrm{~nm}$ of gold onto a glass substrate using physical vapor deposition system and were made immediately before use. This protocol, commonly used in the literature $[10,11]$, provides reproducible Au (111) surfaces with high crystallographic quality, low roughness and with a defined geometry (disk of $0.2 \mathrm{~cm}^{2}$ ). They don't undergo post-treatment after completion.

\subsection{SAMs elaboration}

C15T SAMs were performed by immersing Au substrates for $15 \mathrm{~min}$ in a millimolar solution of C15T in methylene chloride.

Mixed C15T/C12SH SAMs were prepared according to two protocols, to obtain SAMs with a random or a segregated distribution:

Protocol 1 - Successive adsorptions (random distribution):

Mixed SAMs were elaborated by immersing Au substrates for 15 min in a millimolar solution of $\mathrm{C} 15 \mathrm{~T}$ in methylene chloride and then in a millimolar solution of $\mathrm{C} 12 \mathrm{SH}$ in methylene chloride. 
In order to obtain the expected C15T surface coverages, the time of immersion in alkanethiol solution was experimentally adjusted. Protocol 2 - Co-adsorption (segregated distribution):

Mixed SAMs were achieved by immersing the Au substrate for 15 min in a millimolar solution of C15T/C12SH in methylene chloride. In order to obtain the expected C15T surface coverages, the proportions of the two components in solution were experimentally adjusted.

The normalized surface coverage $(\theta)$ of electroactive species is defined by the ratio of the experimental surface coverage $(\Gamma)$ to the maximum surface coverage $\left(\Gamma_{\max }\right)$ according to $\theta=\Gamma / \Gamma_{\operatorname{mgx}} . \Gamma$ is determined by integration of the voltammetric signals of SAMs $\left(\Gamma=\frac{Q}{n+F S}=\frac{1}{n F S} \int i d t\right)$. At $293 \mathrm{~K}, \Gamma_{\max }$ was estimated to $5.0 \pm 0.110^{-10} \mathrm{~mol} \mathrm{~cm}^{-2}$ [12].

\subsection{Electrochemical experiments}

Electrochemical experiments were carried out with a Biologic SP-300 potentiostat in a glove box containing dry, oxygen-free $(<1 \mathrm{ppm})$ argon. Cyclic voltammetry was performed in a three-electrode cell controlled at a temperature of $293 \mathrm{~K}$. Working electrodes were functionalized gold substrates. Counter electrodes were platinum plates. Reference electrodes were $\mathrm{Ag} / \mathrm{AgNO}_{3}\left(0.01 \mathrm{M} \mathrm{CH}_{3} \mathrm{CN}\right)$.

Based on repetitive measurements, absolute errors on potentials and on intensities were found to be $3 \mathrm{mV}$ and $0.2 \mu \mathrm{A}$ respectively at $20 \mathrm{mV} . \mathrm{s}^{-1}$.

Cyclic voltammograms (CVs) were recorded in dry HPLC-grade in mixture of methylene chloride $\left(\mathrm{CH}_{2} \mathrm{Cl}_{2}\right)$ and acetonitrile $\left(\mathrm{CH}_{3} \mathrm{CN}\right)$, with tetrabutylammonium hexafluorophosphate $\left(\mathrm{Bu}_{4} \mathrm{NPF}_{6}-0.1 \mathrm{M}\right)$ as supporting electrolyte.

The following sequence of [methylene chloride]/[acetonitrile] ratio is applied to each electrode: $100 \%, 90 \%, 70 \%, 50 \%, 30 \%, 10 \%$, and $0 \%$. The volume of the electrolyte medium is maintained at $20 \mathrm{ml}$.

\section{Generalized lateral interactions model (GLIM)}

Previous studies show that the electrochemical behaviors of TEMPO SAMs can be explained by the generalized lateral interactions model, according to the main following hypotheses [5]:

The electroactive centers are distributed on substrate with a unimodal statistical distribution of electroactive neighbors. A parameter $\phi(\theta)$, between 0 and 1, defined for a normalized surface coverage $\theta$, quantifies the segregation level of the electroactive centers. For a randomly distributed SAM, $\phi(\theta)=\theta$,

- The sum of normalized surface coverage $\theta_{O}$ and $\theta_{R}$ of oxidized (O) and reduced $(\mathrm{R})$ species is constant and equal to $\theta$,

- The surface occupied by one molecule of $O$ is equal to the surface occupied by one molecule of $R$,

- The electrochemical rate constant $k_{s}$ is independent of the coverage,

$a_{\mathrm{OO}}, a_{R R}$ and $a_{\mathrm{OR}}$ are the interaction constants between molecules of $\mathrm{O}$, molecules of $\mathrm{R}$ and molecules of $\mathrm{O}$ and R, respectively. $a_{i j}$ is positive for an attraction and negative for a repulsion. The $a_{i j}$ values are assumed to be independent of the potential and distribution.

With this model, the i-E characteristic (IUPAC convention) can then be written:

$\mathrm{i}(\mathrm{t})=-\mathrm{nFAk}_{\mathrm{s}} \Gamma_{m}\left(\begin{array}{l}\theta_{\mathrm{O}}(\mathrm{t}) \eta^{-\alpha} \exp \left(-2 \mathrm{a}_{\mathrm{OO}} \frac{\phi\left(\theta_{\mathrm{T}}\right)}{\theta_{\mathrm{T}}} \theta_{\mathrm{O}}-2 \mathrm{a}_{\mathrm{OR}} \frac{\phi\left(\theta_{T}\right)}{\theta_{\mathrm{T}}} \theta_{\mathrm{R}}\right) \\ -\theta_{\mathrm{R}}(t) \eta^{1-\alpha} \exp \left(-2 \mathrm{a}_{\mathrm{RR}} \frac{\phi\left(\theta_{\mathrm{T}}\right)}{\theta_{\mathrm{T}}} \theta_{R}-2 \mathrm{a}_{\mathrm{RO}} \frac{\phi\left(\theta_{\mathrm{T}}\right)}{\theta_{\mathrm{T}}} \theta_{\mathrm{O}}\right.\end{array}\right)$, with $\left\{\begin{array}{l}\mathrm{n}, \mathrm{F}, \mathrm{A}, \mathrm{k}_{s}, \mathrm{R}, \mathrm{T}, \mathrm{E}, \mathrm{E}_{0} \text { and } \mathrm{t} \text { have their usual meanings } \\ \eta=\exp \left(-\alpha \frac{\mathrm{nF}}{\mathrm{RT}}\left(\mathrm{E}-\mathrm{E}_{0}^{\prime}\right)\right) ; \mathrm{E}^{0^{\prime}}=\mathrm{E}^{0}+\frac{\mathrm{RT}}{\mathrm{nF}} \ln \left(\frac{\mathrm{K}_{\mathrm{R}}}{\mathrm{K}_{\mathrm{O}}}\right)\end{array}\right.$

For a full reversible reaction, two parameters, $\mathrm{G}$ and $\mathrm{S}$, defined as global interaction constants, can be introduced:

$\mathrm{G}=\mathrm{a}_{\mathrm{OO}}+\mathrm{a}_{\mathrm{RR}}-2 \mathrm{a}_{\mathrm{OR}}$ et $\mathrm{S}=\mathrm{a}_{\mathrm{RR}}-\mathrm{a}_{\mathrm{OO}}(|\mathrm{G}|$ and $|\mathrm{S}| \leq 2)$.

Full width at half maximum (FWHM), peak potential $\left(E_{p}\right)$ and peak current $\left(i_{p}\right)$ of cyclic voltammograms are defined as:

$\mathrm{i}_{p}\left(\phi\left(\theta_{\mathrm{T}}\right), \theta_{\mathrm{T}}\right)=\frac{\mathrm{n}^{2} \mathrm{~F}^{2} \mathrm{vA} \Gamma_{m}}{\mathrm{RT}} \frac{\theta_{\mathrm{T}}}{2\left(2-\mathrm{G} \phi\left(\theta_{\mathrm{T}}\right)\right)}$

$\mathrm{E}_{\mathrm{p}}\left(\phi\left(\theta_{\mathrm{T}}\right)\right)=\mathrm{E}_{0}^{\prime}+\frac{\mathrm{RT}}{\mathrm{nF}} \mathrm{S} \phi\left(\theta_{\mathrm{T}}\right)$

$\operatorname{FWHM}\left(\phi\left(\theta_{\mathrm{T}}\right)\right) \stackrel{\left|\mathrm{G} \phi\left(\theta_{\mathrm{T}}\right)<1\right| \mathrm{RT}}{\approx} \frac{\mathrm{RT}}{\mathrm{nF}}\left(2 \ln (2 \sqrt{2}+3)-\frac{3 \sqrt{2}}{2} \mathrm{G} \phi\left(\theta_{\mathrm{T}}\right)\right)$

G parameter defines the shape of cyclic voltammograms and S parameter their peak positions. It should be noted that these interaction constants are not related to direct interactions between the electroactive molecules, but rather global interactions between these molecules, the electrolytic medium and electrolytic anions during the electrochemical process. Therefore, if we change the solvent, interaction constants must also change, what we have seen [3] with nitroxyl radical self-assembled monolayers tested in methylene chloride $(G=1.1 ; S=-1.1)$ and acetonitrile $(G=-0.64$; $S=0.64$ ).

Based on this fact, the purpose of this work is to provide evidence of a continuity of these constants when you have to go from one solvent to another in the case of miscible solvents whatever the surface distribution of electroactive centers is and to show if this distribution is not altered during the experiment.

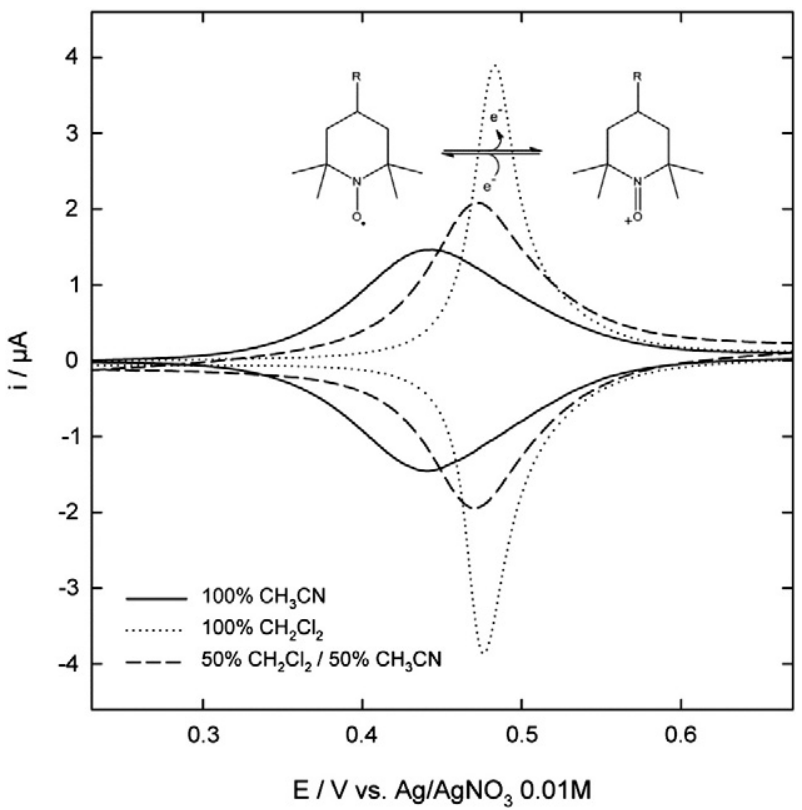

Fig. 1. CVs of C15T SAMs obtained in $0.1 \mathrm{MnBu}_{4} \mathrm{NPF}_{6} / \mathrm{CH}_{2} \mathrm{Cl}_{2}(\ldots .),. 0.1 \mathrm{MnBu}_{4} \mathrm{NPF}_{6} /$ (50\% $\mathrm{CH}_{2} \mathrm{Cl}_{2} / 50 \% \mathrm{CH}_{3} \mathrm{CN}$ ) (_--) and $0.1 \mathrm{M} \mathrm{nBu}_{4} \mathrm{NPF}_{6} / \mathrm{CH}_{3} \mathrm{CN}$ (_). $\mathrm{v}=20 \mathrm{mV} \cdot \mathrm{s}^{-1}$. 


\section{Experimental results}

\subsection{C15T SAMs}

The shape of voltammetric waves and the linear dependency between peak intensities and scan rates are the characteristic of
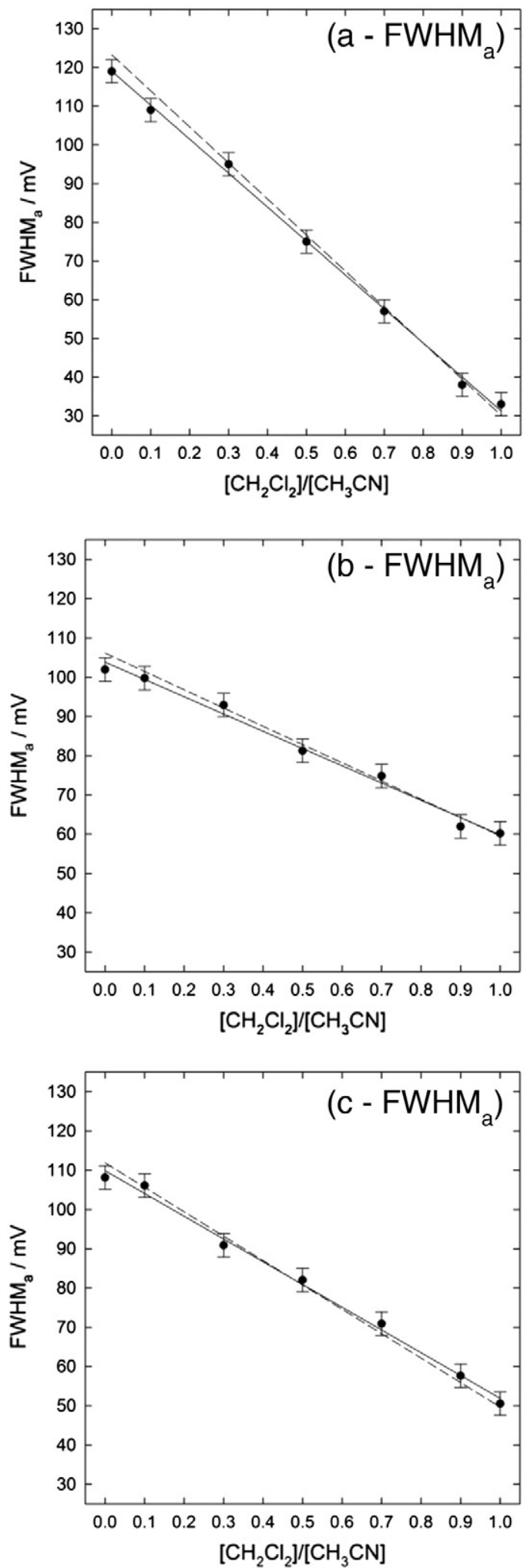

surface-confined redox species (Fig. 1). As previously observed [4], CVs of C15T SAMs exhibit a reversible one-electron process centered at $0.49 \mathrm{~V}$ (vs. $\left.\mathrm{Ag} / \mathrm{AgNO}_{3}\right)$ in $0.1 \mathrm{M} \mathrm{Bu}_{4} \mathrm{NPF}_{6} / \mathrm{CH}_{2} \mathrm{Cl}_{2}\left(100 \% \mathrm{CH}_{2} \mathrm{Cl}_{2}\right)$ and the shape of CVs depends on interaction constants $(\mathrm{G}=1.1 ; \mathrm{S}=-1.1-$ Eqs. (1)-(3)). Experimental surface coverages, $\Gamma$, were calculated around $4.8 \pm 0.210^{-10} \mathrm{~mol} \mathrm{~cm}^{-2}$, closed to $\Gamma_{\max }$ taking into account errors [12].
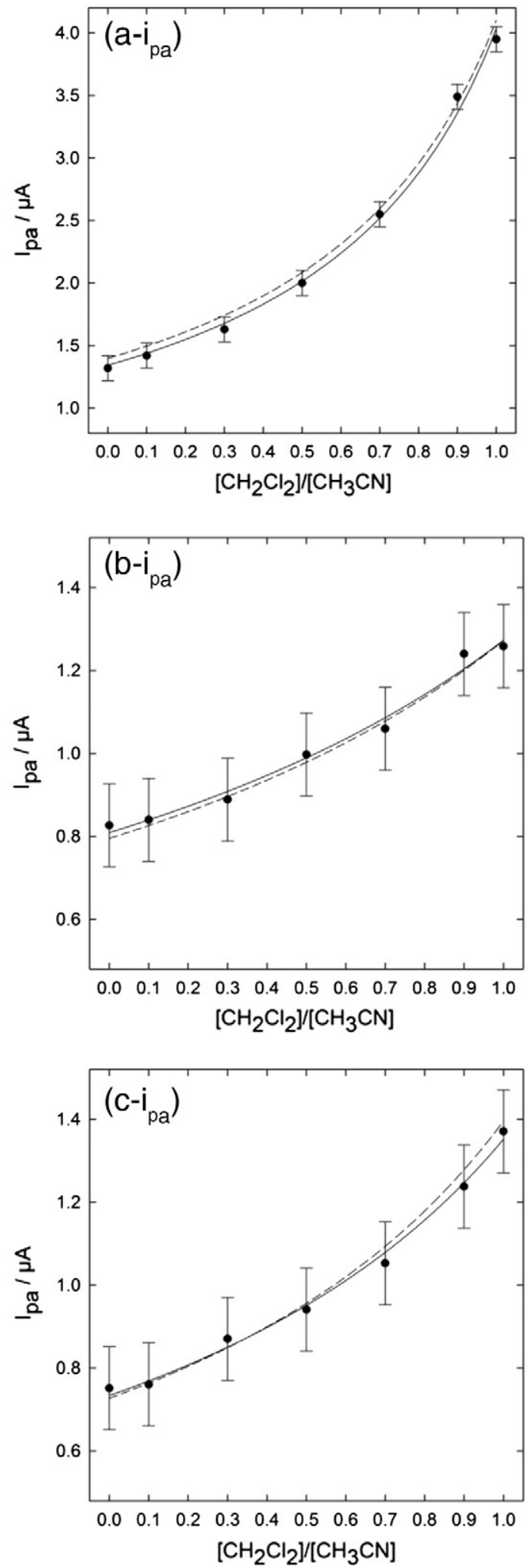

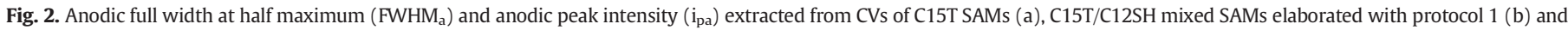

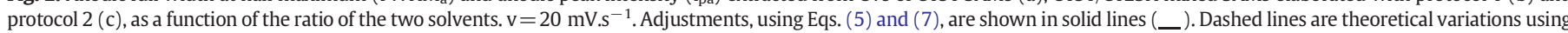
$G_{\mathrm{CH}_{2} \mathrm{Cl}_{2}}=-S_{\mathrm{CH}_{2} \mathrm{Cl}_{2}}=1.1$ and $G_{\mathrm{CH}_{3} \mathrm{CN}}=-S_{\mathrm{CH}_{3} \mathrm{CN}}=-0.64$. 
Table 1

Generalized lateral interactions model parameters of SAMs extracted from CVs.

\begin{tabular}{|c|c|c|c|c|c|c|}
\hline SAM type & $\theta_{T}$ & $\phi\left(\theta_{T}\right)$ & $G_{\mathrm{CH}_{2} \mathrm{Cl}_{2}}$ & $G_{\mathrm{CH}_{3} \mathrm{CN}}$ & $\mathrm{S}_{\mathrm{CH}_{2} \mathrm{Cl}_{2}}$ & $\mathrm{~S}_{\mathrm{CH}_{3} \mathrm{CN}}$ \\
\hline C15T (compact monolayer) & 1 & 1 & $1.08_{ \pm 0.02}$ & $-0.56_{ \pm 0.02}$ & $-1.09_{ \pm 0.02}$ & $0.74_{ \pm 0.07}$ \\
\hline C12SH/C15T (random distribution) & 0.5 & 0.49 & $1.09_{ \pm 0.05}$ & $-0.56_{ \pm 0.05}$ & $-1.10_{ \pm 0.04}$ & $0.56_{ \pm 0.08}$ \\
\hline C12SH/C15T (segregated distribution) & 0.48 & 0.67 & $1.04_{ \pm 0.03}$ & $-0.58_{ \pm 0.03}$ & $-1.03_{ \pm 0.03}$ & $0.62_{ \pm 0.05}$ \\
\hline
\end{tabular}

When the ratio $R=$ [methylene chloride]/[acetonitrile] is modulated from $100 \%$ to $0 \%$ according to the following sequence, [100\%, $90 \%, 70 \%$, $50 \%, 30 \%, 10 \%, 0 \%]$, voltammograms gradually change to obtain a typical voltammogram of $\mathrm{C} 15 \mathrm{~T}$ in $100 \% \mathrm{CH}_{3} \mathrm{CN}$. Fig. 1 clearly shows this phenomenon for three electrolyte media (100\% $\mathrm{CH}_{2} \mathrm{Cl}_{2}, 50 \% \mathrm{CH}_{2} \mathrm{Cl}_{2} / 50 \%$ $\mathrm{CH}_{3} \mathrm{CN}$ and $100 \% \mathrm{CH}_{3} \mathrm{CN}$ ).

To characterize more precisely the trends, FWHM and $i_{p}$ parameters were extracted from experimental CVs for each electrolyte medium. Peak potential, $E_{p}$, is not followed because it depends on many parameters, like $E_{0}^{\prime}$ and reference potential, that can fluctuate with electrolyte medium. Fig. 2a (black circles) clearly shows a linear dependence of FWHM with the ratio of the two solvents. For $i_{p}$, the trend is not clearly identified but presents a monotonic variation.

\section{2. $\mathrm{C} 12 \mathrm{SH} / \mathrm{C} 15 \mathrm{~T}$ mixed SAMs}

To investigate the role of surface distribution of electroactive centers, mixed SAMs were also tested with the same procedure. Two mixed SAMs, with nearly the same surface coverage, were elaborated with the protocols 1 and 2 in order to obtain random and segregated distributions respectively.

Experimental surface coverages, $\Gamma$, were calculated in $0.1 \mathrm{M}$ $\mathrm{Bu}_{4} \mathrm{NPF}_{6} / \mathrm{CH}_{2} \mathrm{Cl}_{2}\left(100 \% \mathrm{CH}_{2} \mathrm{Cl}_{2}\right)$. For protocol 1 (random distribution), $\Gamma_{1}=2.4 \pm 0.210^{-10} \mathrm{~mol} \mathrm{~cm}^{-2}$, corresponding to $\theta_{1}=0.50$. For protocol 2 (segregated distribution), $\Gamma_{2}=2.3 \pm 0.210^{-10} \mathrm{~mol} \mathrm{~cm}^{-2}$, corresponding to $\theta_{2}=0.48$. With Eq. (3) and the values of experimental FWHM and $i_{p}$, we can deduce the segregation level of each mixed SAMs. For SAMs elaborated with protocol $1, \phi=0.49 \approx \theta$, which indicates that all electroactive centers are randomly distributed on the electrode. For SAMs elaborated with protocol 2, $\phi=0.67>\theta$, which indicates that electroactive immobilized centers are segregated on the electrode.

As for C15T SAMs, FWHM and $i_{p}$ parameters were extracted from experimental CVs for each electrolyte medium. Fig. 2b-c (black circles) shows that the trends are similar to those observed for SAMs of $\mathrm{C} 15 \mathrm{~T}$ and the ranges of the variations depend, in a first approximation, of the surface coverage and segregation factor.

\section{Discussion}

\subsection{Adaptation of the generalized lateral interactions model}

If we consider that interaction constants ( $G$ and $S$ ) are highly dependent of the solvent used, we can assume that when the electrolytic medium is composed of two miscible solvents, $G$ and $S$ are depending of the ratio of the two solvents.

Experimental results show that the variations of FWHM and $i_{p}$ are directly linked to surface coverage, segregation factor and the ratio of the two solvents.

To interpret these results, additional hypotheses must be considered to use the model:

1. When two solvents are miscible, the mixture can be considered as a single solvent with its own interaction constants $G$ and $S$ which are independent of the distribution (see GLIM hypotheses).

2. $G$ and $S$ values are dictated by a linear function of the ratio (R) of the two solvents.

3. The distribution of electroactive centers is stable, so $\phi$ is a constant.
Considering these assumptions:

$\mathrm{G}(\mathrm{R})=\mathrm{a}_{\mathrm{G}} \cdot \mathrm{R}+\mathrm{b}_{\mathrm{G}} \quad \mathrm{S}(\mathrm{R})=\mathrm{a}_{\mathrm{S}} \cdot \mathrm{R}+\mathrm{b}_{\mathrm{S}}$.

To determine $a_{G}, b_{G}, a_{S}$ and $b_{S}$, initial and final conditions are required in $\mathrm{CH}_{2} \mathrm{Cl}_{2}$ and $\mathrm{CH}_{3} \mathrm{CN}$ :

$\left.\begin{array}{l}\mathrm{G}(1)=\mathrm{G}_{\mathrm{CH}_{2} \mathrm{Cl}_{2}} \quad \mathrm{G}(0)=\mathrm{G}_{\mathrm{CH}_{3} \mathrm{CN}} \\ \mathrm{S}(1)=\mathrm{S}_{\mathrm{CH}_{2} \mathrm{Cl}_{2}} \mathrm{~S}(0)=\mathrm{S}_{\mathrm{CH}_{3} \mathrm{CN}}\end{array}\right\} \Rightarrow\left\{\begin{array}{l}\mathrm{a}_{\mathrm{G}}=\mathrm{G}_{\mathrm{CH}_{2} \mathrm{Cl}_{2}}-\mathrm{G}_{\mathrm{CH}_{3} \mathrm{CN}} \\ \mathrm{b}_{\mathrm{G}}=\mathrm{G}_{\mathrm{CH}_{3} \mathrm{CN}} \\ \mathrm{a}_{\mathrm{S}}=\mathrm{S}_{\mathrm{CH}_{2} \mathrm{Cl}}-\mathrm{S}_{\mathrm{CH}_{3} \mathrm{CN}} \\ \mathrm{b}_{\mathrm{S}}=\mathrm{S}_{\mathrm{CH}_{3} \mathrm{CN}}\end{array}\right.$

$\mathrm{G}$ and $\mathrm{S}$ can be formulated like these equations:

$\mathrm{G}(\mathrm{R})=\mathrm{G}_{\mathrm{CH}_{3} \mathrm{CN}}+\left(\mathrm{G}_{\mathrm{CH}_{2} \mathrm{Cl}_{2}}-\mathrm{G}_{\mathrm{CH}_{3} \mathrm{CN}}\right) \cdot \mathrm{R}=\mathrm{R} \cdot \mathrm{G}_{\mathrm{CH}_{2} \mathrm{Cl}_{2}}+(1-\mathrm{R}) \cdot \mathrm{G}_{\mathrm{CH}_{3} \mathrm{CN}}$

$\mathrm{S}(\mathrm{R})=\mathrm{S}_{\mathrm{CH}_{3} \mathrm{CN}}+\left(\mathrm{S}_{\mathrm{CH}_{2} \mathrm{Cl}_{2}}-\mathrm{S}_{\mathrm{CH}_{3} \mathrm{CN}}\right) \cdot \mathrm{R}=\mathrm{R} \cdot \mathrm{S}_{\mathrm{CH}_{2} \mathrm{Cl}_{2}}+(1-\mathrm{R}) \cdot \mathrm{S}_{\mathrm{CH}_{3} \mathrm{CN}}$.

If we combine Eqs. (1)-(4), characteristic parameters of the voltammograms can be defined as a function of R:

$\mathrm{i}_{p}\left(\phi\left(\theta_{\mathrm{T}}\right), \theta_{\mathrm{T}}, \mathrm{R}\right)=\frac{\mathrm{n}^{2} \mathrm{~F}^{2} \mathrm{vA} \Gamma_{m}}{\mathrm{RT}} \frac{\theta_{\mathrm{T}}}{2\left(2-\left(\mathrm{R} \cdot \mathrm{G}_{\mathrm{CH}_{2} \mathrm{Cl}_{2}}+(1-\mathrm{R}) \cdot \mathrm{G}_{\mathrm{CH}_{3} \mathrm{CN}}\right) \phi\left(\theta_{T}\right)\right)}$

$\mathrm{E}_{p}\left(\phi\left(\theta_{\mathrm{T}}\right), \theta_{\mathrm{T}}, \mathrm{R}\right)=\mathrm{E}_{0}^{\prime}+\frac{\mathrm{RT}}{\mathrm{nF}}\left(\mathrm{R} \cdot \mathrm{S}_{\mathrm{CH}_{2} \mathrm{Cl}_{2}}+(1-\mathrm{R}) \cdot \mathrm{S}_{\mathrm{CH}_{3} \mathrm{CN}}\right) \phi\left(\theta_{T}\right)$

$\operatorname{FWHM}\left(\phi\left(\theta_{T}\right), \theta_{T}, \mathrm{R}\right) \stackrel{\left|\mathrm{G} \phi\left(\theta_{T}\right)<1\right|}{\approx} \frac{\mathrm{RT}}{\mathrm{nF}}\left(2 \ln (2 \sqrt{2}+3)-\frac{3 \sqrt{2}}{2}\left(\mathrm{R} \cdot \mathrm{G}_{\mathrm{CH}_{2} \mathrm{Cl}_{2}}+(1-\mathrm{R}) \cdot \mathrm{G}_{\mathrm{CH}_{3} \mathrm{CN}}\right) \phi\left(\theta_{T}\right)\right)$.

\subsection{Experimental data vs. model}

To confront the model and experimental data, $G_{\mathrm{CH}_{2} \mathrm{Cl}_{2}}, G_{\mathrm{CH}_{3} \mathrm{CN}}$,

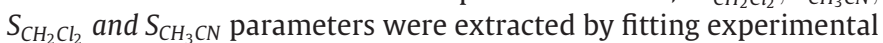
results of FWHM and $i_{p}$ with Eqs. (5) and (7) (Table 1). Adjustments are shown in Fig. 2.

The values of $\mathrm{G}_{\mathrm{CH}_{2} \mathrm{Cl}_{2}}, \mathrm{G}_{\mathrm{CH}_{3} \mathrm{CN}}, \mathrm{S}_{\mathrm{CH}_{2} \mathrm{Cl}_{2}}$ and $\mathrm{S}_{\mathrm{CH}_{3} \mathrm{CN}}$ (Table 1) are very close to those obtained in the previous works (methylene chloride $(G=1.1 ; S=-1.1)$ and acetonitrile $(G=-0.64 ; S=0.64))$. Theoretical variations are shown in dashed lines in Fig. 2, using these previous values of $\mathrm{G}$ and $\mathrm{S}$ and values of $\theta_{T}$ and $\phi\left(\theta_{T}\right)$. In addition, the distribution independence of $\mathrm{G}_{\mathrm{CH}_{2} \mathrm{Cl}_{2}}, \mathrm{G}_{\mathrm{CH}_{3} \mathrm{CN}}, S_{\mathrm{CH}_{2} \mathrm{Cl}_{2}}$ and $\mathrm{S}_{\mathrm{CH}_{3} \mathrm{CN}}$ (Table 1) validates the model and its hypotheses. This means that the mixture of these two miscible solvents can be considered as a single solvent with its own interaction constants, G and S, defined as a linear function of the ratio of the two solvents. The distribution of electroactive centers does not influence the linearity and is not modified by the sequence of electrolytic medium used for the electrochemical characterizations.

Why this model is efficient? Firstly, the unimodal statistic distribution of electroactive centers [6] permits to reduce the spacial environment of all entities in a unique redox spacial environment. This is the scientific basis of the lateral interactions model initiated by E. Laviron [13] and generalized recently by us [5]. Secondly, the miscibility of the two solvents is similar, in a first approximation, to a random distribution of each solvent molecule in the surface of the monolayer. In 
summary, all electroactive molecules have a spatial environment [redox; solvent] almost identical, regardless of the distribution of redox sites, which is a prerequisite for using the generalized lateral interaction model.

\section{Conclusion}

Generalized lateral interactions model was validated when electrolytic medium was not only composed of one solvent but a mixture of two miscible solvents. This work provides evidence of a linearity of the interaction constants, when you have to go from one solvent to another, as a function of the ratio of the two solvents. We also demonstrated that this linearity is not dictated by the distribution of electroactive centers in the case of mixed SAMs. This work confirms that the distribution of electroactive centers is not altered by the sequence of electrolytic medium used for the electrochemical characterizations.

\section{Acknowledgments}

The authors express their gratitude to Flavy Alévêque for her critical reading of the manuscript.

\section{References}

[1] R.G. Nuzzo, D.L. Allara, Journal of the American Chemical Society 105 (1983) 4481-4483.

[2] J.C. Love, L.A. Estroff, J.K. Kriebel, R.G. Nuzzo, G.M. Whitesides, Chemical Reviews 105 (2005) 1103-1169.

[3] O. Aleveque, P.Y. Blanchard, T. Breton, M. Dias, C. Gautier, E. Levillain, F. Seladji, Electrochemistry Communications 11 (2009) 1776-1780.

[4] O. Aleveque, F. Seladji, C. Gautier, M. Dias, T. Breton, E. Levillain, Chemphyschem 10 (2009) 2401-2404

[5] O. Aleveque, P.Y. Blanchard, C. Gautier, M. Dias, T. Breton, E. Levillain, Electrochemistry Communications 12 (2010) 1462-1466.

[6] O. Aleveque, C. Gautier, M. Dias, T. Breton, E. Levillain, Physical Chemistry Chemical Physics 12 (2010) 12584-12590.

[7] T. Fuchigami, T. Shintani, A. Konno, S. Higashiya, T. Nonaka, Denki Kagaku (Electrochemistry) 65 (1997) 506.

[8] Y. Kashiwagi, K. Uchiyama, F. Kurashima, J.-i. Anzai, T. Osa, Analytical Sciences 15 (1999) 907-909.

[9] Y. Kato, Y. Shimizu, L. Yijing, K. Unoura, H. Utsumi, T. Ogata, Electrochimica Acta 40 (1995) 2799-2802.

[10] F. Schreiber, Progress in Surface Science 65 (2000) 151-256.

[11] G.E. Poirier, Chemical Reviews 97 (1997) 1117-1128.

[12] O. Alévêque, P.-Y. Blanchard, T. Breton, M. Dias, C. Gautier, E. Levillain, Electrochemistry Communications 16 (2012) 6-9.

[13] E. Laviron, Journal of Electroanalytical Chemistry and Interfacial Electrochemistry 52 (1974) 395-402. 